Preprints of the

Max Planck Institute for

Research on Collective Goods

Bonn 2010/04

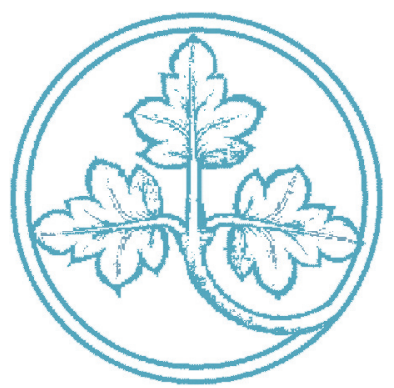

Optimal observability in a linear income tax

Joel Slemrod

Christian Traxler

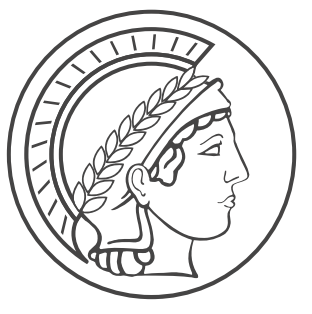




\section{Optimal observability in a linear income tax}

Joel Slemrod / Christian Traxler

December 2009 


\title{
Optimal observability in a linear income tax
}

\author{
Joel Slemrod \\ University of Michigan \\ Christian Traxler \\ Max Planck Institute for Research on Collective Goods
}

December 21, 2009

\begin{abstract}
We study the optimal observability of the tax base within the standard linear income tax problem, where observability is determined by the government's investment into the accurate measurement of the tax base. We characterize the optimal level of observability and derive a new expression for the optimal progressivity, which - in addition to the standard equity efficiency trade-off - accounts for the limited accuracy of an income tax system.
\end{abstract}

Keywords: optimal linear income taxation; observability; tax enforcement. JEL classification: H21, H11, D8 


\section{Motivation}

The optimal income tax literature is based on the notion that, although raising resources from a lump-sum tax is non-distortionary, an income tax may be appropriate in a society of abilityheterogeneous individuals that values equality. Mirrlees (1971) first rigorously analyzed this question in the context of a general income tax, and much subsequent literature examined it assuming that the tax system features a proportional income tax and a lump-sum element. A key insight of this literature is that, other things equal, a larger behavioral response to marginal tax rates - a greater manipulability of the tax base - makes higher marginal rates less attractive.

Another desirable quality of tax bases that has attracted less academic attention is what we call observability. Basing tax liability on difficult-to-observe quantities introduces capriciousness into the distribution of tax burdens. Assigning tax burdens capriciously may undermine the legitimacy of government. It also produces uncertainty, may raise inequality and can affect labor supply. But assigning tax burdens in a non-capricious way requires that the tax base is measured with some degree of accuracy. Many tax policy choices must therefore trade off manipulability and observability. The widespread use of presumptive income taxes, where tax liability ultimately depends on presumed correlates of income, is an excellent illustration of this tradeoff.

In this paper we re-examine the optimal linear income tax when income is not perfectly observed. Income is assessed for tax purposes with some error which can be interpreted as the outcome of taxpayers' efforts to conceal income, the tax authority's imperfect attempts to assess income and enforce tax liability, the tax court's rulings, and so on. The limited observability implies that the income tax is not perfectly enforced, in the sense that taxable income may differ from actual income. This inaccuracy also means that taxation introduces uncertainty over aftertax income, which provides disutility to risk-averse individuals. In addition, it raises the dispersion of after-tax incomes, as individuals with identical incomes are taxed differently, making the income tax less redistributive than otherwise.

We incorporate these arguments into the optimal policy problem by allowing the government to expend real resources to choose the optimal level of observability, reflected in the inaccuracy of income measurement. Then we characterize optimal observability, which is determined by the trade-off between the social costs from allowing more inaccuracy (and thus, a higher risk imposed on taxpayers and more inequality in after-tax income) and the net revenue gains from having a cheaper-to-administer, but more capricious, tax system. 


\section{Related Literature}

The first wave of optimal income tax literature made an extreme assumption about the availability of information: ability cannot be observed by the tax authority at any cost, but income is observed costlessly. Neither is literally true, of course. A notable early exception is Stern (1982), who considers (exogenous) errors in the allocation of lump-sum transfers targeted to the poor. A somewhat distinct strand of literature has addressed whether introducing randomness in taxation can ever increase social welfare. Weiss (1976), Stiglitz (1982), as well as Brito, Hamilton, Slutsky, and Stiglitz (1995) argue that it can, because of its positive effect on distorted labor supply, while Yitzhaki (1987) and Hellwig (2007) demur. ${ }^{1}$ Scotchmer and Slemrod (1989) and Scotchmer (1989) investigate the effect of random income assessments on evasion and redistribution, respectively, but not from a normative perspective.

Recently, Kopczuk (2001) examines optimal enforcement and optimal progressivity of a linear income tax when avoidance behavior varies for given ability due to either tastes or access to technology. With heterogeneity in access to technology, a high taxable income characterizes both individuals with high skill levels and people who lack access to avoidance opportunities. Only the former is a justifiable reason to redistribute. Optimal progressivity declines with this type of heterogeneity because taxable income becomes a less reliable indicator of well-being. Kaplow (1998), whose analysis is closely related to our own approach, obtains a similar result. Discussing optimal accuracy and complexity for a given tax rate, Kaplow notes that "a more accurate income tax improves the resulting distribution of income” (p. 62). This is the case, because with greater accuracy high- (low-) income individuals are more (less) likely to pay high taxes. Our analysis embeds Kaplow's observation into the optimal linear income tax problem. ${ }^{2}$

\section{Analysis}

Consider a large economy of heterogeneous agents with measure one. Abilities, equal to the wage rate $w$, are distributed according to the cdf $F(w)$. Individual preferences over labor $L$ and

\footnotetext{
${ }^{1}$ See also Pestieau, Possen, and Slutsky (1998) and Reinganum and Wilde (1988).

${ }^{2}$ We also follow Kaplow (1998, and elsewhere) in characterizing this issue without introducing a separate spcial crieterion of horizontal equity: "A more traditional ex post perspective might emphasize that, under an inaccurate regime, equals are treated unequally when income is measured inaccurately, a problem usually characterized as horizontal inequality. But the preceding analysis suggests that the welfare cost of inaccuracy may be understood as arising from greater inequality (vertical inequity). The after-tax income distribution in the inaccurate regime can be derived from that in the accurate regime by adding a random component to each individual's income. Accordingly, the income distribution in the inaccurate regime involves greater dispersion and thus greater inequality.” (Kaplow, 1998, p. 66)
} 
disposable income $C$ are given by $U(C, L) .{ }^{3}$ In principle, labor income $w L$ is taxed at rate $t$, but the tax authority faces constraints in observing taxable income. Due to limited observability, the tax base is assessed with an error $\eta$ and the tax liability becomes $t(w L+\eta){ }^{4}$ The error is distributed according to the density function $h(\eta, \sigma)$, where $\sigma$ denotes the variance and $H(\eta, \sigma)$ the cdf. The expected error is zero, $\int \eta h(\eta, \sigma) d \eta=0$, i.e., we assume that taxable income equals actual income on average. Facing an inaccurate tax system, the problem of a risk-averse taxpayer is

$$
\max _{C, L} \int U(C(w, \eta), L) d H \quad \text { s.t. } C=w L-t(w L+\eta)+g=(1-t) w L-t \eta+g,
$$

where $g$ is a lump-sum transfer. The lump-sum element of the tax system involves no observability issues (i.e., for $g>0$, we assume identification of eligibility and delivery to be costless). Labor supply is chosen before the error in assessing the taxable income is realized. Focusing on interior solutions, the optimal labor supply $L^{*}$ is then given by

$$
\int\left(U_{C}(1-t) w+U_{L}\right) d H=0 .
$$

Ex ante, when individuals choose their labor supply, they are only heterogeneous with respect to their abilities. Ex post, after labor choices have been made and errors have realized, inequality in after-tax income emerges both from heterogeneous abilities and the capricious taxation of equal incomes.

As in the standard linear income tax problem, the government chooses the two parameters of a linear income tax schedule to maximize social welfare. In addition, it chooses the observability of the tax base by investing $K(\sigma)$. For a given population of taxpayers, this continuously differentiable function (with $K^{\prime}<0 \leq K^{\prime \prime}$ ) measures the expenditures that are necessary to establish a certain level of observability, corresponding to an inaccuracy $\sigma{ }^{5}$ As $t w L^{*}$ is independent of the realization of the (zero mean) error, the government budget constraint simplifies to

\footnotetext{
${ }^{3}$ In our model, manipulability arises through changes in labor supply; more generally it arises from any behavior that affects taxable income (Saez, Slemrod, Giertz, 2009).

${ }^{4}$ The results derived below do not change qualitatively if we consider an error term whose size depends on the tax base. A simple case would be a multiplicative error with tax liability equal to $t w L(1+\eta)$. The error in tax liability would be increasing in actual income. Higher effort would then imply a larger variance of after-tax income, which would directly affect the labor choice of risk-averse agents.

${ }^{5}$ See Kleven and Kopczuk (2008) for a related approach to the choice of transfer program complexity.
} 


$$
\iint\left(t w L^{*}+t \eta-g-K(\sigma)-R\right) d H d F=\int\left(t w L^{*}-g-K(\sigma)-R\right) d F \geq 0,
$$

where $R$ denotes an exogenous revenue requirement. We can state the policy problem as

$$
\max _{g, t, \sigma} \int\left(\int \Psi\left(U\left(C, L^{*}\right)\right) d H(\eta, \sigma)+\lambda\left[t w L^{*}-g-K(\sigma)-R\right]\right) d F(w) .
$$

The first-order conditions for interior solutions to the problem are

$$
\begin{aligned}
& g: \int\left(\int \Psi^{\prime} U_{C} d H(\eta, \sigma)+\lambda\left[-1+t w \frac{\partial L^{*}}{\partial g}\right]\right) d F(w)=0 \\
& t: \int\left(\int-\Psi^{\prime} U_{C}\left(w L^{*}+\eta\right) d H(\eta, \sigma)+\lambda\left[w L^{*}+t w \frac{\partial L^{*}}{\partial t}\right]\right) d F(w)=0 \\
& \sigma: \int\left(\int \Psi(.) \frac{\partial h(\eta, \sigma)}{\partial \sigma} d \eta+\lambda\left[-K^{\prime}(\sigma)+t w \frac{\partial L^{*}}{\partial \sigma}\right]\right) d F(w)=0 .
\end{aligned}
$$

Optimal transfer. Rearranging (3a) and substituting for (1), we obtain the familiar condition for the optimal transfer,

$$
\bar{b}=\lambda \text {. }
$$

The social marginal valuation of income for a $w$-type and the average valuation are defined as

$$
b(w) \equiv \int \Psi^{\prime} U_{C} d H+\lambda t w \frac{\partial L^{*}}{\partial g} \text {, and } \bar{b} \equiv \int b(w) d F \text {, respectively. }
$$

Expression (4) says that the optimal transfer is such that the average social marginal valuation of the subsidy equals the social costs, as captured in $\lambda$. The only difference from the standard solution for the optimal transfer is that now $b(w)$ depends on the accuracy of the tax system: an individual's after-tax income (and therefore the marginal utility from an increase in the transfer) depends on the distribution of the error. For an infinitesimally small tax inaccuracy $(\sigma \rightarrow 0)$, $b(w)$ reduces to the standard term for the social marginal valuation. Hence, condition (5) accommodates the benchmark result for the case of a tax system with perfect observability.

Optimal tax rate. Making use of (1) and (4) and following Dixit and Sandmo (1977), we get from (3b) an expression for the optimal tax rate, ${ }^{6}$

\footnotetext{
${ }^{6}$ A detailed appendix containing the derivation of this and all other results is available from the authors.
} 


$$
t=\frac{-\operatorname{Cov}\left(w L^{*}, b(w)\right)-\int \psi(w) d F}{\lambda \int w S_{L}(w) d F}
$$

where $S_{L}(w) \equiv-\partial L^{*} /\left.\partial t\right|_{U_{0}}>0$ denotes the substitution effect. Expression (6) resembles the standard solution to the optimal tax in that the first term in the numerator and the denominator capture the trade-off between the distributional objectives and the welfare cost that results from the (compensated) responsiveness of labor supply.

With an imperfect income tax base assessment, a new term appears in the numerator: $\int \psi(w) d F>0$, where $\psi(w) \equiv \int \Psi^{\prime} U_{C} \eta d H$. This term depicts the marginal social costs from the tax system's inaccuracy, i.e., the increase in the variance of after-tax income generated by a marginal increase in the tax rate. The new term takes account of two effects. First, with a higher tax rate, individuals bear more risk from a given degree of inaccuracy. ${ }^{7}$ Second, due to inaccurate tax base assessment there is a larger dispersion of after-tax incomes within each $w$-class. Both effects run against the (strictly positive) first term in the numerator, the welfare gains from redistribution reflected in the covariance term. ${ }^{8}$ Put simply, inaccuracy reduces the effectiveness of progressive taxation in generating a more equal after-tax income distribution. Hence, the optimal tax rate (and the optimal demogrant) depend not only on the manipulability of the tax base, but also on its observability. While a higher manipulability increases the deadweight loss of a given tax rate per dollar raised, more observability decreases the social costs from inaccurate taxation.

It is worth stressing that, unlike for the case of a perfectly accurate income tax system, there is an asymmetry in the impact of the policy instruments $g$ and $t$. In contrast to a change in the lump-sum transfer, an increase in the tax rate, additionally triggers a higher variance in the tax payments, $t \eta$. While the redistributive effects from changes in the transfer and the tax rate are taken up in $\bar{b}$ in (4) and the covariance term in (6), respectively, the marginal social costs from inaccurate taxation enter the expression for the optimal tax rate separately. ${ }^{9}$

\footnotetext{
${ }^{7}$ In contrast to Domar and Musgrave (1944), a higher tax rate increases rather than decreases the risk borne by individuals.

${ }^{8}$ Recall that, under the standard assumptions of $w L^{*}$ being non-decreasing in $w$, the covariance term is non-positive for a social marginal valuation of income that is decreasing in $w$.

${ }^{9}$ Although the capricious assessment of the tax base affects neither (4) nor the covariance term in (6) explicitly, it indirectly affects both via its effect on $b(w)$.
} 
Optimal observability. Compared to the standard optimal income taxation problem, the government has an additional instrument that allows it to control the extent of inaccuracy of tax base assessment. By re-arranging expression (3c), we can obtain the following expression for the optimal observability, expressed as the inverse of the measure of inaccuracy $\sigma$ :

$$
\begin{aligned}
& \frac{1}{\sigma}=-\frac{1}{\lambda} \frac{\iint \Psi(U(.)) \frac{\partial h(\eta, \sigma)}{\partial \sigma} d \eta d F}{K(\sigma) \varepsilon_{K, \sigma}-\int t w L^{*} \varepsilon_{L, \sigma} d F} \\
& \text { with } \varepsilon_{K, \sigma} \equiv-\frac{\partial K}{\partial \sigma} \frac{\sigma}{K}>0 \text { and } \varepsilon_{L, \sigma} \equiv-\frac{\partial L^{*}}{\partial \sigma} \frac{\sigma}{L^{*}} .
\end{aligned}
$$

The right-hand side of (7) gives the ratio of the marginal welfare costs to the marginal social benefits of the revenue generated by changing the tax system's accuracy. All else equal, more inaccuracy in taxation means more risk to the individuals and a larger dispersion of aftertax incomes. The higher these costs from a capricious assessment of the tax base, the lower will be the optimal inaccuracy $\sigma$ or, equivalently, the higher will be the optimal observability in the tax system. This also means that an increase in the government's preference for equality (a more concave social welfare function) implies a higher level of optimal observability.

The denominator of the formula in (7) contains two revenue effects from increasing the inaccuracy (weighted by $\lambda$, the marginal social value of revenue). On the one hand, it is less costly to administer a less accurate tax system. This is measured by $\varepsilon_{K, \sigma}$, the elasticity of the tax administration costs $K$ with respect to $\sigma$. By assumption, the elasticity is strictly positive. The higher $\varepsilon_{K, \sigma}$, i.e., the more expensive it is to achieve greater accuracy, the lower is the optimal observability. On the other hand, any change in the accuracy may alter labor supply and thus tax revenues. ${ }^{10}$ This second revenue effect is captured by the elasticity of the labor supply with respect to $\sigma$, denoted $\varepsilon_{L, \sigma}$. Whenever labor supply is decreasing in the variance, the elasticity is positive (and vice versa). The higher is the average elasticity of labor with respect to $\sigma$, the higher is the optimal level of observability. ${ }^{11}$

\footnotetext{
${ }^{10}$ Because there is a constant marginal tax rate and the error has zero mean, a reduced variance in the tax base does not directly (i.e., other than through its effect on labor supply and the cost of achieving the lower variance) affect revenues. This would not be true with a graduated tax schedule.

${ }^{11}$ Even if it were costless to reach perfect accuracy $\left(\varepsilon_{K, \sigma}=0\right)$, it is not necessary optimal to do so. The reason is, that - depending on the curvature of the utility functions determining risk aversion and thus $\varepsilon_{L, \sigma}$ - inaccuracy might support labor supply; see Weiss (1976) but also Hellwig (2007).
} 


\section{Conclusion}

Modern tax analysis has focused on the constraints put on redistributive taxation by the manipulability of tax bases and made simple, extreme assumptions about the observability of tax bases. But to achieve a tax system's objectives, tax liability should, ceteris paribus, be triggered by bases that are readily observable by the tax authority. This paper addresses this issue in a simple model where the two tax instruments are a proportional income tax and a lump-sum demogrant. The former is redistributive but relies on a base that is both manipulable and inaccurately measured, although the inaccuracy can be reduced by the tax authority at some cost. The lump-sum transfer is not redistributive, but introduces no randomness into tax liability. Thus, the tradeoffs among redistribution, manipulability and accuracy are starkly illustrated: the redistributive but manipulable base is of limited observability. The more costly it is to achieve observability, the higher is the inaccuracy and the less redistributive is the optimal tax system.

Our analysis leaves some questions for future research. The first is whether there is an inherent relationship between the manipulability, observability and redistributiveness of tax bases. Some tax bases chosen for their relative observability are known to be highly manipulable - think of capital gains realizations versus capital gains accruals. Yet in other cases a relatively more observable base seems to less manipulable - think of a presumptive income tax based on restaurant square footage versus restaurant income, discussed in Yitzhaki (2007). The presumptive tax base is relatively observable and unmanipulable, and would be ideal except that it "presumably" falls short on grounds of redistribution - it is not highly correlated with true income.

Second, the parallel analysis of the observability and manipulability of alternative tax bases would be facilitated if the former could be captured by a unit-free measure the way that manipulability is captured by a behavioral response elasticity. This would simplify the characterization of optimal tax systems and clarify the tradeoffs that arise in tax policy design.

Finally, we stress that the approach taken in this paper assumes that the observability of a tax base can be chosen independently from the other policy variables. In the light of the model's reduced-form interpretation of observability - that it is driven by, e.g., occupational choices, individual evasion behaviour as well as government's enforcement efforts - this modeling aspect appears critical. It relies on the non-trivial assumption that all agents' actions that affect observability are independent of the tax rate: agents cannot manipulate observability. A challenge for future research is to study the robustness of our findings to extending the analysis to allow for endogenous responses that shape observability, manipulability, and in turn the redistributiveness of the optimal tax system. 


\section{References}

Brito, D.L., Hamilton, J.H., Slutsky, S.M., Stiglitz, J.E., 1995. Randomization in optimal income tax schedules. Journal of Public Economics 56, 189-223.

Dixit, A., Sandmo, A., 1977. Some simplified formulae for optimal income taxation. Scandinavian Journal of Economics 79, 417-423.

Domar, E.D., Musgrave, R. A., 1944. Proportional income taxation and risk-taking. Quarterly Journal of Economics 58, 388-422.

Hellwig M., 2007. The undesirability of randomized income taxation under decreasing risk aversion. Journal of Public Economics 91, 791-816.

Kaplow, L., 1998. Accuracy, complexity, and the income tax. Journal of Law, Economics and Organization 14, 61-83.

Kleven, H., Kopczuk, W., 2008. Transfer program complexity and the take up of social benefits. NBER Working Paper No. 14301.

Kopczuk, W., 2001. Redistribution when avoidance behavior is heterogeneous. Journal of Public Economics 81, 51-71.

Mirrlees, J. A., 1971. An exploration in the theory of optimum income taxation. Review of Economic Studies 38, 175-208.

Pestieau, P., Possen, U.M., Slutsky, S.M., 1998. The value of explicit randomization in the tax code. Journal of Public Economics 67, 87-103.

Reinganum, J. F, Wilde, L. L., 1988. A note on enforcement uncertainty and taxpayer compliance. Quarterly Journal of Economics 103, 793-798.

Saez, E., Slemrod, J., Giertz, S., 2009. The elasticity of taxable income with respect to marginal tax rates: A critical review. NBER Working Paper No. 15012.

Scotchmer, S., 1989. Who profits from taxpayer confusion? Economics Letters 29, 49-55.

Scotchmer, S., Slemrod, J., 1989. Randomness in tax enforcement. Journal of Public Economics 38, 17-32.

Stern, N., 1982. Optimum taxation with errors in administration. Journal of Public Economics 17, 181-211.

Stiglitz, J.E., 1982. Utilitarianism and horizontal equity: The case of random taxation. Journal of Public Economics 18, 1-33

Weiss, L., 1976. The desirability of cheating incentives and randomness in the optimal income tax. Journal of Political Economy 84, 1343-52.

Yitzhaki, S., 1987. On the excess burden of tax evasion. Public Finance Quarterly 15, 123-137.

Yitzhaki, S., 2007. Cost-benefit analysis of presumptive taxation. FinanzArchiv 63, 311-326. 